\title{
UM OLHAR SOBRE OS MIGRANTES BRASILEIROS NO JAPÃO
}

\author{
Elisa Sasaki *
}

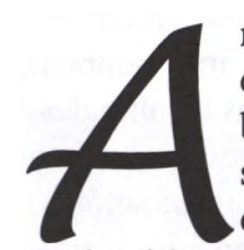

migração internacional contemporânea de brasileiros ao Japão, que se iniciou em meados dos anos 80, ficou conhecida como 'Movimento Dekassegui'. Originalmente, a palavra japonesa 'dekassegui' significa "trabalhar fora de casa". Ela é composta por dois ideogramas (kanji): 'deru', que significa sair e 'kassegu', que significa trabalhar, ganhar dinheiro. No Japão referia-se aos trabalhadores que saíam temporariamente de suas regiões de origem e iam a outras mais desenvolvidas, sobretudo aqueles provenientes do norte e nordeste do Japão, durante o rigoroso inverno que interrompia suas produções agrícolas no campo. Este mesmo termo passou a ser empregado para definir os descendentes de japoneses - nikkei ou nikkeijin - que vão trabalhar no Japão em busca de melhores salários, empregando-se em ocupações de baixa qualificação caracterizadas pelos japoneses como "3K" - Kitanai (sujo), Kiken (perigoso) e Kitsui (penoso). Posteriormente, os brasileiros se encarregaram de acrescer mais dois Ks - Kirai (detestável) e Kibishii (exigente) (Kawamura, 2003). Nesse sentido, o termo 'dekassegui' remete à idéia de um trabalho temporário para em seguida retornar à sua região de origem. Além disso, traz embutida uma imagem pejorativa daqueles que se sujeitam a trabalhos recusados por muitos ${ }^{1}$.

No início do "Movimento Dekassegui" nos anos 80 , essas idéias pareciam ser pertinentes, pois nesse período, os que iam ao Japão trabalhar, não eram bem vistos ${ }^{2}$, mas sim como "um mal necessário". Havia uma demanda por mão-de-obra barata e não-qualificada mas não queriam forasteiros. As primeiras notícias sobre a ida de brasileiros descendentes de japoneses para trabalhar temporariamente no Japão apareceram nos meados da década de 80 , representando um movimento tímido, em termos de volume. Em geral, eles não tiveram grandes problemas burocráticos para entrar no território japonês, pois seu perfil era de: nipo-descendentes das primeiras gerações - issei e/ou nissei. Logo, muitos tinham nacionalidade japonesa ou dupla nacionalidade, podendo ingressar no Japão como japoneses. Apresentavam, em geral, idade avançada; eram chefes de família e casados; sabiam falar japonês e pretendiam permanecer apenas temporariamente no Japão.

A partir da primeira metade dos anos 90, assim que o fluxo de brasileiros para o Japão se massificou, começaram a germinar as primeiras redes sociais migratórias de brasileiros, entrando em cena novos atores sociais, tais como: os candidatos a trabalhadores migrantes; as pequenas empresas japonesas demandando mãode-obra estrangeira e, os agentes intermediários. Estes últimos tinham grande atuação nesse cenário, explorando os migrantes estrangeiros e obtendo uma margem de lucro considerável com o recrutamento dos mesmos. Concomitantemente, com intuito de amparar os trabalhadores migrantes, também começaram a surgir no cenário Centros de atendimento, informação, orientação e apoio aos trabalhadores migrantes, quer por parte de iniciativa governamental municipal, quer de vários grupos de voluntários sem fins lucrativos. Um exemplo disso é o Centro de Informação e Apoio ao Trabalhador no Exterior (CIATE), criado em São Paulo (Brasil). De acordo com Ricardo Sasaki (2002, pp. 254-255), este Centro "fornece informações e orientações sobre ofertas de emprego no Japão; a cultura, os usos e costumes, e a vida cotidiana no Japão; legislação trabalhista japonesa; assessoria jurídica; sistema educacional no Japão; seguro social (saúde, aposentadoria, desemprego, acidentes 
de trabalho) japonês; restituição de aposentadoria e solicitação de pensão; imposto de renda (bi-tributação) e demais tributos no Japão".

No Japão, há mais de seiscentas entidades similares, principalmente onde há significativa presença de brasileiros, assim como estrangeiros de outras nacionalidades na condição de trabalhador migrante. Em geral essas entidades podem estar vinculadas à prefeitura local, às associações civis, regionais e locais, grupos voluntários que oferecem informações e orientações de diversas naturezas trabalhista, jurídica, educacional, cultural, social, ensino de língua, cultura cotidiana (como coleta de lixo), etc.

No passado, a política imigratória japonesa se centrou na idéia de controle e monitoramento de estrangeiros, como atenta Kashiwazaki (2002). Enquanto o controle de fronteiras era a maior preocupação para o governo central, foi surgindo a necessidade de uma política de integração em âmbito local e nacional. Na ausência de uma política de integração coerente em nível nacional, os governos locais têm se defrontado com a acomodação de residentes estrangeiros recémchegados, que têm se estabelecido em grande número. Isso se aplica particularmente às cidades que têm experimentado um rápido influxo de imigrantes, como as cidades e regiões industriais na parte central do Japão, onde os trabalhadores nikkeis têm se estabelecido em grande número. Moradia, educação dos filhos de migrantes, saúde são alguns dos assuntos que tem sido alvo de atenção. Comparando com o governo central, os governos locais têm inovado suas políticas para acomodar os residentes estrangeiros. Nesse sentido, muitos governos locais têm instaurado assembléias para os cidadãos estrangeiros ou reuniões similares nos últimos anos (Ikegami, 2001; Pak, 2001). Essas respostas administrativas em nível local também refletem uma velha reivindicação por parte dos coreanos que buscam ser reconhecidos como membros da comunidade local sem considerar sua nacionalidade.

\section{ONDE ESTÃO OS BRASILEIROS}

Em 2004, registrou-se o total de 286.557 brasileiros residentes nesse país (Japan Immigration Association 2005), sendo o terceiro maior contingente de estrangeiros no Japão, atrás de Coréia (do Sul e do Norte) e da China.

Os brasileiros concentram-se na região central da Ilha Principal (Honshu) do Japão, onde se encontram as cidades industriais. As principais províncias com brasileiros residentes registrados em 1994 são: Aichi, Shizuoka, Kanagawa, Saitama e Gunma que, juntas, reúnem mais da metade de toda população brasileira presente no Japão.

Nagano é uma das províncias que chama a atenção no que se refere à crescente presença de brasileiros em seu território. Enquanto em 1994 despontava apenas em sétimo lugar (tendo recebido pouco mais de 6.500 brasileiros), ao longo dos anos de 1990 foi ganhando destaque, passando o ocupar a terceira posição em 1998 (com 14.670), superada apenas por Aichi (aproximadamente 41.000) e Shizuoka (mais de 31.000). A partir deste ano, Nagano consolida-se como a terceira província japonesa com maior número de brasileiros, fato que se explica por sediar indústrias do setor de componentes eletrônicos, as quais também passaram a contratar mão-deobra estrangeira.

Dentre as cidades com maior concentração de brasileiros destacam- se: Hamamatsu (Shizuoka) - cujo montante em 2000 era de $11 \mathrm{mil}$, atingindo 13.800 em 2004 - seguida por Toyohashi, Toyota, Nagoya e Okazaki, todas da província de Aichi, onde predomina a indústria automobilística, com grande número de empresas subcontratadas que alimentam a produção em cadeia deste setor nessa região. É também aqui que se constata a preocupação por parte do governo local em promover uma política de integração dos estrangeiros para a vida comunitária local ou regional, como apontado anteriormente.

Os brasileiros estão concentrados na região central do Japão, mas também se encontram em diversas localidades. Isso deve estar relacionado com o fato de haver empregos em outros setores, como o de serviços, alimentícios [frigoríficos, supermercados, panificação, bentô (marmitas), etc.]. Nesse sentido, podemos dizer que, embora os brasileiros ainda sejam alocados no setor manufatureiro (automobilístico, eletrônicos, etc.), ao longo do tempo eles têm ocupado empregos nos outros setores citados. Pode-se dizer que o seu deslocamento geográfico está muito mais ligado à mudança de emprego do que a outros motivos - por exemplo, reunião familiar - uma vez que este depende da ação das empreiteiras às quais estão vinculados.

\section{DE BRASILEIROS PARA BRASILEIROS}

$\mathrm{Na}$ sociedade receptora japonesa, surgiam notícias sobre restaurantes e lojas de produtos brasileiros atendendo ao público consumidor, especialmente brasileiro. São pequenos negócios de brasileiros para os brasileiros. "Alguns migrantes que chegaram há mais tempo, após alguns anos como operários de fábrica, conseguiram se estabelecer como proprietários (sob o 
aval de um proprietário japonês) de restaurantes, mercearias, lojas de produtos e objetos brasileiros, lojas de roupas, lojas de carros usados, vídeo locadoras, bares, cabeleireiros etc." (Kawamura, 2003, p.148). Segundo Kawamura, se antes a interação dos brasileiros no Japão se limitava a agências de turismo, recrutadores, embaixada e consulados brasileiros, mais recentemente, isso veio se complexificando cada vez mais. Uma parte crescente e significativa deste contingente veio desenvolvendo estratégias de (sobre)vivência a longo prazo na sociedade japonesa, estabelecendo-se como comerciantes, pequenos industriais, grandes empresários, prestadores de serviços profissionais, culturais e artísticos desde esportista, cantor, dançarino, modelo, gerente, técnico de informática, até professor, advogado, jornalista, representante religioso, etc. - para um mercado consumidor brasileiro (e peruano) em expansão, formando e fortalecendo os "redutos" próprios desses migrantes.

A vivência cotidiana dos brasileiros no Japão é facilitada pela constituição de redes sociais que propiciam uma infra-estrutura para atendê-los: há disponibilidade de mercadorias, serviços de informação, comunicação e documentação, escolas brasileiras, restaurantes, bares, diversão, etc. Diversos aspectos favorecem, então, a permanência destes migrantes no Japão, apesar da dificuldade de inserção cultural na sociedade japonesa. A partir disso, desencadeouse um processo de institucionalização do movimento de deslocamento entre Brasil e Japão, compondo e consolidando uma rede social migratória cada vez mais complexa.

Acompanhando o fluxo do movimento migratório deste contingente, notamos uma mudança no perfil do brasileiro no Japão: gerações mais avançadas (segunda e terceira); proporção sexual relativamente equiparada; faixa etária mais jovem, sem o domínio da língua - já que também pela grande presença de brasileiros no Japão diminui a necessidade dos novos migrantes de saber falar a língua japonesa -; mais solteiros e recém-casados (casados há pouco tempo ou com filhos pequenos) entre os compatriotas no Japão (não significando necessariamente apenas estes); caráter mais familiar do que individual; presença de não-descendentes entre os migrantes (que iam como cônjuges dos descendentes de japoneses); aumento na duração da estadia dos brasileiros no Japão (Sasaki, 2000).

\section{AUMENTO NO NÚMERO DE BRASILEIROS PERMANENTES NO JAPÃO}

100 CIDADES NO JAPÃO COM MAIOR PRESENÇA DE BRASILEIROS

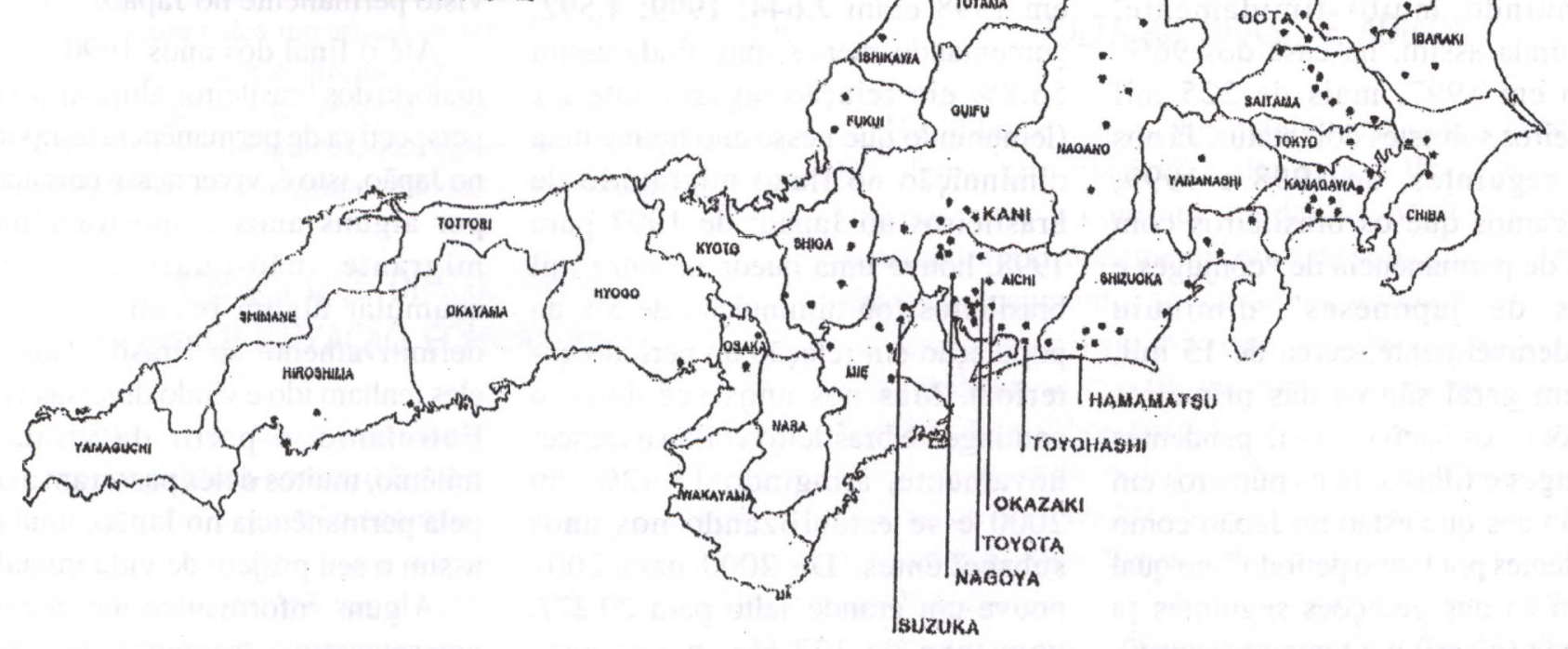


A mudança de perspectiva temporal dos brasileiros no Japão, que inicialmente era claramente temporária e passou a se estender por mais tempo, pode ser verificada na lista de Status de Permanência no Japão, na qual encontramos várias categorias. Dentre elas, sobressaem-se duas: "os cônjuges e filhos de japoneses" e os "residentes por longa duração" que boa parte dos brasileiros adquiriu.

Somando estas duas categorias, dentre o total de brasileiros residentes no Japão, mais de $90 \%$ enquadram-se nestas duas categorias e, os que vão como 'dekasseguis', devem permanecer nesse país sob esses status, uma vez que, nestas condições, não há restrições quanto a atividades a exercer, diferentemente daqueles que têm status de permanência temporária de três meses. Em outras palavras, embora nem todos os brasileiros presentes no Japão sejam 'dekasseguis', a grande maioria é ou pode estar no Japão como trabalhador migrante barato e desqualificado.

Em 1994, mais de 154 mil brasileiros estavam sob estas duas categorias de permanência, representando $97 \%$ do total. Nos anos seguintes, essa proporção vai diminuindo muito timidamente, mas ainda assim, na casa dos $96 \%$, tendo em 1997, mais de $225 \mathrm{mil}$ brasileiros sob estes dois status. Já nos anos seguintes, de 1998 e 1999, verificamos que os brasileiros com status de permanência de "cônjuges e filhos de japoneses" diminuiu consideravelmente, cerca de $15 \mathrm{mil}$, que em geral são os das primeiras gerações - os isseis e seus dependentes (cônjuges e filhos). Já os números em relação aos que estão no Japão como "residentes por longo período", no qual cabem os das gerações seguintes [a segunda (nissei) e a terceira (sansei), como foi dito anteriormente], mostram-nos um crescimento gradativo, sendo que de 1999 para 2000 , houve um salto de mais de 20 mil brasileiros apenas nessa categoria. Mesmo somando essas duas categorias citadas acima, nos últimos anos, elas têm decrescido: se até 1999, juntas representavam cerca de $96 \%$, a partir de 2000 , essa cifra foi decrescendo gradualmente: em 2000 elas passaram a totalizar 94,0\%; em $200190 \%$; em $200286 \%$ e em 2003 82\%. De 2001 a 2002 é que se verifica uma queda maior em termos de números absolutos, cerca de 9 mil dentre estes dois status referidos.

Em contrapartida, nota-se um aumento substantivo no status de permanência 'residentes em caráter permanente': de 1995 para 1996, notamos um salto de 474 para 931 brasileiros nessa categoria, correspondendo a uma taxa de crescimento anual desse período de $96,4 \%$, praticamente duplicando o volume. No ano seguinte de 1997, a tendência ao crescimento nesse status continua expressiva: de 931 no ano anterior passou para 1.686 , aumentando $81,1 \%$. O número de brasileiros residentes permanentes continua crescendo significativamente nos últimos anos: em 1998 eram 2.644; 1999: 4.592, aumentando menos mas ainda assim $56,8 \%$ em relação ao ano anterior (lembrando que nesse ano houve uma diminuição no fluxo migratório de brasileiros ao Japão: de 1997 para 1998, houve uma queda de onze mil brasileiros (ou diminuição de $5 \%$ da população em relação ao período anterior). Mas nos anos seguintes o contingente brasileiro voltou a crescer novamente, atingindo $13,42 \%$ em 2000 e se estabilizando nos anos subseqüentes. De 2000 para 2001 houve um grande salto para 20.277 , com taxa de $123,6 \%$, e nos anos seguintes houve um contínuo aumento: em 2002, 31.203 brasileiros eram residentes permanentes, atingindo 52.581 em 2004. Em outras palavras, nos primeiros anos do terceiro milênio, os brasileiros residentes com caráter permanente têm aumentado cerca de 10 mil a cada ano, revelando mudança nos projetos de vida destes, diante da mudança de perspectiva temporal do processo migratório.

Segundo Edson Mori (2002, p.245), que analisou o aspecto econômico do Movimento Dekassegui, a diminuição no fluxo migratório de brasileiros para o Japão em 1998 quando se registrou pela primeira vez na história desse contingente uma queda no número total de entrada de brasileiros nesse país - deve estar relacionada à estabilização da economia brasileira ao adotar o Plano Real e, concomitantemente, à crise na economia japonesa e à subseqüente reestruturação da indústria japonesa, que acabou levando a uma diminuição na demanda por trabalhadores migrantes estrangeiros. Por conta disso, nesse período, houve também uma significativa diminuição na emissão de novos vistos aos brasileiros. Além disso, no final dos anos 90, houve um aumento de brasileiros requerendo visto permanente no Japão.

Até o final dos anos 1990, a vasta maioria dos brasileiros alimentava uma perspectiva de permanência temporária no Japão, isto é, viver nesse país apenas por alguns anos como trabalhador migrante não-qualificado para acumular algum pecúlio e retornar definitivamente ao Brasil, ainda que eles tenham ido e vindo diversas vezes. Entretanto, a partir da virada do milênio, muitos deles passaram a optar pela permanência no Japão, mudando assim o seu projeto de vida inicial.

Alguns informantes qualificados ${ }^{3}$ apresentaram outros possíveis motivos para o aumento de brasileiros 
portadores de vistos permanentes, o que não necessariamente reflete uma mudança de projeto. Um deles disse que havia uma relação de "custo / benefício" na obtenção de visto permanente, pois é mais barato do que pedir visto de cônjuge ou filhos de japoneses ou de longo período (de 1 a 3 anos). Estes dois últimos tipos de visto têm que ser renovados de tempo em tempo, à medida que se expira e, portanto, a cada renovação, paga-se uma taxa. Já para o visto permanente, paga-se a taxa apenas uma vez. Uma vez que o brasileiro - assim como os outros estrangeiros - esteja no Japão um longo período, por exemplo mais de três anos, estará apto a requerer o visto permanente. Um outro informante disse que estava tendo congestionamento na fila de vistos de longo período. Assim, o próprio funcionário da imigração japonesa perguntava aos brasileiros (e estrangeiros) se estavam no Japão por um bom tempo. Para estes, emitia-lhe o visto permanente e assim aliviava as outras filas. Um terceiro participante disse que há um grande número de brasileiros não descendentes pedindo visto permanente, para poder se divorciar do/a seu/sua cônjuge descendente. Isto porque, como já foi dito, para migrar legalmente ao Japão, deve-se ter necessariamente ascendência japonesa ou então estar casado/a com um/a descendente. Com o visto permanente, essas pessoas não dependem mais do vínculo conjugal com o/a descendente para permanecer legalmente no país hospedeiro. Estas informações de migrantes experientes ou daqueles que estão envolvidos com a migração brasileira ao Japão, embora neste momento não tenhamos dados pesquisados e comprovados, são indicadores interessantes para pensarmos possíveis e variadas razões que estão por trás dos números apresentados oficialmente, como no caso, do aumento de brasileiros portadores de visto permanente nos últimos anos.

\section{FAIXA ETÁRIA DA POPULAÇÃO BRASILEIRA}

O contínuo aumento de brasileiros como residentes permanentes no Japão se reflete nos dados sobre a faixa etária deste contingente. Podemos observar um aumento significativo de população jovem: em 1994 os jovens brasileiros, muitos dos quais devem ter nascido no Japão, entre 0 a 14 anos representava $9,0 \%$ em relação ao total de brasileiros presentes no Japão, isto é, pouco mais de $14 \mathrm{mil}$. Essa porcentagem foi aumentando gradualmente, até que em 2004, essa faixa etária compõe mais $15 \%$ do total de brasileiros, com mais de 43 mil jovens.

Já os que estão na faixa etária de 15 a 19 anos, em 1994 eram 12.409, correspondendo a $7,8 \%$ da população brasileira total presente no Japão. Essa porcentagem cresceu ligeiramente nos próximos anos, atingindo $8,3 \%$ (19.276) em 1997. No ano seguinte de 1998, apresentou uma taxa de crescimento anual negativo nesse período de $-9,1 \%$, decrescendo para 17.517. Isso continuou no ano seguinte de 1999, caindo mais ainda para 15.583 jovens brasileiros. Em 2000, o crescimento desta faixa etária é retomado, aumentando 2.632 jovens em relação ao ano anterior. Mas nos próximos anos, esse grupo etário apresenta um decréscimo novamente: em 2002, assim como em 2004, os jovens de 15 a 19 anos representavam $6,0 \%$ dentre o total da população brasileira total.

A faixa etária dos 20 aos 59 anos, considerada a população economicamente ativa e produtiva, representa a maior parcela da população brasileira. Em 1994, esse grupo etário compreendia mais de 131 mil brasileiros, representando $82,4 \%$ do total dos brasileiros residentes no Japão. Embora em números absolutos, essa faixa apresente um crescimento contínuo, exceto no ano de 1998, a sua proporção em relação ao total está tendendo a declinar, chegando em 2004 com uma proporção menor de $76,4 \%$.

Podemos relacionar isso com o aumento da população mais jovem como já vimos anteriormente. Aliás, o grupo de jovens brasileiros de 0 a 14 anos foi a parte da população que não sofreu decréscimo no ano de 1998 , como aconteceu com todas as demais faixas etárias. Podemos inferir que aqueles que se encontravam no Brasil - seja o migrante experiente, isto é, já esteve no Japão anteriormente, retornou ao Brasil e decidiu ir novamente ao Japão trabalhar, seja o novo candidato a trabalhador migrante que estava tentando ir trabalhar pela primeira vez ao Japão - tiveram muita dificuldade de conseguir visto de entrada ao Japão assim como conseguir emprego nesse país em 1998 e 1999, à medida que a conjuntura econômica japonesa não estava favorável, sentindo os efeitos da crise asiática. Por outro lado, muitas famílias residentes no Japão com filhos menores que não saíram do país, relacionado ao expressivo aumento de brasileiros com visto permanente, podem justificar o crescimento contínuo de jovens ao longo de todos esses anos.

Embora o número de brasileiros acima de 60 anos apresente números bem menores, vale notar o aumento deste contingente ao longo desses anos. Em 1994, menos de 1\% faziam parte deste grupo etário, com 1.433 brasileiros. Seguindo a tendência geral de crescimento da população brasileira total, este grupo também sofre um decréscimo no ano de 1998, mas em 
seguida retoma o seu crescimento, chegando em 2004 a quintuplicar a população de 1994: 7.554 brasileiros acima de 60 anos estavam residindo no Japão. Vale notar que embora essa população não seja uma população economicamente ativa, à medida que a população de crianças vai aumentando, a presença de pessoas nessa faixa etária passa a fazer parte da composição familiar, pois elas podem ajudar na manutenção do cotidiano na casa, como cuidar das crianças e dos afazeres domésticos, enquanto outros membros produtivos da família trabalham nas fábricas. Além disso, deve-se considerar o envelhecimento natural dos migrantes que eram antes produtivos e que acabaram permanecendo no Japão.

\section{CONSIDERAÇÕES FINAIS}

De um modo geral, o que mais se destaca nesse vôo panorâmico pelo processo migratório entre Brasil e Japão na virada do século XX para XXI foi a mudança de perspectiva temporária - o que inicialmente pretendia-se temporário, os brasileiros passaram a permanecer cada vez mais no Japão. Isso refletiu no número de aumento de brasileiros residentes permanentes no Japão, assim como no aumento da faixa etária da população brasileira no Japão, o que por sua vez, tem implicado em implantações de políticas locais e regionais onde a sua presença se concentra - no cinturão industrial do país, isto é, na região central do Japão.

A expectativa temporária inicial foi se perdendo de vista ao longo do tempo, cabendo assim, atentar às diferentes conotações do termo "dekassegui" que foi mudando, desde que se adotou no início do fluxo migratório, como vimos no início deste texto. Deve-se ter claro, no entanto, que os significados são datados, contextualizados e sócio-culturalmente construídos. Ao mesmo tempo que as categorias têm um aspecto bastante fluido, isto é, usa-se muito sem ter uma definição muito clara, acabam sendo socialmente compartilhadas e naturalizadas - não só pelos próprios migrantes e a comunidade japonesa e/ ou nipo-brasileira, mas também pelos estudiosos do tema.

De qualquer forma, durante a experiência migratória, dada a rotina de trabalho intenso e cansativo, aflora um sentimento de 'gaman' que em japonês, segundo o verbete do dicionário Michaelis de japonês / português (2003, p.112), quer dizer: "paciência; perseverança, resistência, tolerância; indulgência; autodomínio; autocontrole; renúncia”. São palavras e sentimentos duros, penosos, tanto que acabamos preferindo colocar, inconscientemente talvez, uns antolhos para poder continuar tendo gaman, em nome do sonho - o futuro dos filhos negligenciando entretanto estes mesmos entes na dura vida cotidiana. Mas mais duro é, imagino eu, ver os efeitos e não poder mais voltar para trás. A vida é tão rara, como canta Lenine, numa música chamada, veja só: 'paciência'.

* Elisa Sasaki é Doutoranda em Ciências Sociais pelo Instituto de Filosofia e Ciências Humanas (IFCH) Universidade Estadual de Campinas (UNICAMP).

\section{NOTAS}

1 - Este texto é resultado de pesquisa financiada pela Fundação de Amparo à Pesquisa do Estado de São Paulo (FAPESP).

2 - Isso porque o fato de ir trabalhar no Japão em ocupações subalternas era algo associado à idéia de fracasso, ferindo o orgulho dos japoneses que no início do século $X X$ imigraram para o Brasil, sendo considerados uma coletividade que obteve um relativo sucesso no país de destino.
3 - São pessoas que se manifestaram durante $\circ$ debate logo após a minha exposição no I Congresso Brasileiro sobre Dekassegui, realizado em Maringá (PR), no dia 27 de outubro de 2005 , organizado pelo SEBRAE. Muitos destes participantes eram os próprios migrantes ou então aqueles que estavam envolvidos de alguma maneira com a migração de brasileiros ao Japão.

\section{REFERÊNCIAS BIBLIOGRÁFICAS}

IKEGAMI, Shiguehiro

(2001) Burajirujin to Kokusaika suru Chiiki Shakai-Kyojû, Kyôiku, Iryô. [O Brasileiro e a Comunidade Local que se Internacionaliza - Moradia, Educação, Saúde]. Tokyo: Akashi Shôten.

JAPAN IMMIGRATION ASSOCIATION

[Zaidan Hônin Nyûkan Kyôkai], 1995 a 2005. Zairyû Gaikokujin Tôkei. [Estatísticas sobre Estrangeiros Residentes no Japão (Relatórios Anuais)].

KASHIWAZAKI, Chikako

(2002) “Japan: From Immigration Control to Immigration Policy?". Migration Information Source. URL (acessado em 17/10/ 04): http://www.migrationinformation. org/Profilesprint.cfm?ID=39

KAWAMURA, Lili

(2003) Para Onde Vão os Brasileiros? Imigrantes Brasileiros no Japão. Campinas: ed. Unicamp, $2^{\mathrm{a}}$ edição revista. (1ª edição: 1999).

MICHAELIS

(2003) Dicionário Prático JaponêsPortuguês. São Paulo: Aliança Cultural Brasil-Japão.

MORI, Edson

(2002) “The Japanese-Brazilian Dekasegi Phenomenon - An Economic Perspective". In: HIRABAYASHI, Lane et al. (eds.), New Worlds, New Lives, Stanford (California): Stanford University Press, pp. 237-248.

PAK, Katherine Tegtmeyer

(2001) "Towards Local Citizenship: Japanese Cities Respond to International Migration". Working Papern.30, The Center for Comparative Immigration Studies (CCIS), University of Califomia at San Diego.

SASAKI, Elisa Massae

(2000) Dekasseguis: Trabalhadores Migrantes Nipo-Brasileiros no Japão. Campinas, Núcleo de Estudos de População (NEPO), UNICAMP, textos NEPO, $\mathrm{n}^{\circ} 39$.

SASAKI, Ricardo

(2002) "Os Problemas que Envolvem os Trabalhadores Brasileiros no Japão". In: Taeco Carignato et al. (orgs.), Psicanálise, Cultura e Migração. São Paulo: YM Editora \& Gráfica, p.239-256. 